\title{
Blunt thoracic aortic injury: challenges of open repair
}

\section{Krishnaprasad Bashyal, Uttam Krishna Shrestha, Kajan Raj Shrestha, Dinesh Gurung, Nikesh Bhandari, Prashiddha Kadel}

Department of Surgery, Manmohan Cardiothoracic Vascular and Transplant Center, Maharajgunj, Kathmandu, Nepal.

Correspondence: Dr. Krishnaprasad Bashyal, Department of Surgery, Manmohan Cardiothoracic Vascular and Transplant Center, Maharajgunj, Kathmandu, Nepal.

Email: drbashyal85@gmail.com

\section{Abstract}

Thoracic aortic injuries are fatal with less than $50 \%$ patients surviving beyond 24 hours even after reaching the hospital if approach is delayed. Rapid transportation, adequate resuscitation, prompt radiological diagnosis, and urgent repair significantly improves outcomes. Even after a good repair, complications such as spinal cord ischemia causing paraplegia and acute lung injury significantly increase the morbidity. Thoracic endovascular repair may appear to be superior to open repair, but its long-term results and efficacy are not well established. We present our experience with open repair in managing this challenging acute emergency and certain measures to avert common but grievous complications.

Keywords: Blunt; Complications; Open repair; Thoracic aortic injury.

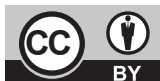

BY DOI: https://doi.org/10.3126/jssn.v23i1.33557

\section{Introduction}

As per the Global Burden of Disease Study of 2017, road traffic accidents (RTA) and trauma were responsible for 16,831 deaths in Nepal. Unintentional injuries like falls and occupational injuries constituted $1.55 \%$ of it. ${ }^{1}$ Blunt thoracic aortic injuries (BTAI) are the second commonest cause of mortality amongst RTA patients as most of them succumb to exsanguination at the site of accident itself. Its management is graded and according to a widely used anatomic classification proposed by Azizzadeh Ali in 2009 grade I injury is defined as intimal tear, grade II as intramural hematoma, grade III as pseudoaneurysm, and grade IV as rupture of thoracic aorta. ${ }^{2}$ We present an unusual cause of grade IV BTAI in a young male which he sustained while on the job and our experience managing this almost fatal, rare injury with an open approach.

\section{Case Report}

A 21 years old male was brought to the emergency department of our hospital (Manmohan Cardiothoracic Vascular and Transplant Center) in a state of shock. History revealed that he was trapped under a huge pile of mud while working, after which he started complaining of heaviness in chest, backache, difficulty in breathing, and dizziness. There was no history of loss of consciousness.
He had a patent airway with Glasgow Coma Scale of 15, but was hemodynamically unstable. Cardiogenic shock was managed appropriately and after resuscitation, the patient underwent computerized tomography (CT) of head, chest and abdomen. Contrast-enhanced CT (CECT) chest showed bilateral hemothorax (in view of trauma) with extravasation of contrast from the descending thoracic aorta (DTA, Figure 1). With the diagnosis of grade IV BTAI, the patient was immediately planned for surgery and rushed to the operating room.

Left thoracotomy at the level of $5^{\text {th }}$ intercostal space (extending to superior axillary region) with femorofemoral partial cardio-pulmonary bypass was performed. Cell-salvage system was used to minimize blood loss. Intraoperatively, there were around 1.5 liters of blood in the left hemithorax. Transection of DTA beyond the level of inferior pulmonary vein was observed. While establishing the distal bypass, woven Dacron graft was interposed using clamp and sew technique (Figure 2).

The post-operative period was initially uneventful and the patient was extubated within 16 hours. From the third post-operative day onwards, he started developing highgrade fever with expectoration of sero-purulent sputum which was sent for culture and sensitivity $(\mathrm{c} / \mathrm{s})$. He was reintubated on the $5^{\text {th }}$ day following persistent fall in oxygen 
levels in blood gas studies despite oxygen supplementation and chest physiotherapy. In view of the patient developing acute lung injury (ALI) and to ascertain graft function, a CECT chest was repeated which revealed diffuse rightsided lung contusion and consolidatory changes with no collection in the thoracic cavity and an intact graft (Figure 3). With the patient showing no clinical improvement in lung function, a bedside bronchoscopy with lavage was done and the fluid was sent for $\mathrm{c} / \mathrm{s}$ after the first sputum sample yielded no growth. Klebsiella pneumoniae was isolated and appropriate antibiotics as per sensitivity were initiated. The patient gradually started improving and was weaned off of ventilator in nine days and after completion of the course of intravenous antibiotics he was discharged on the $21^{\text {st }}$ post-operative dav (POD)

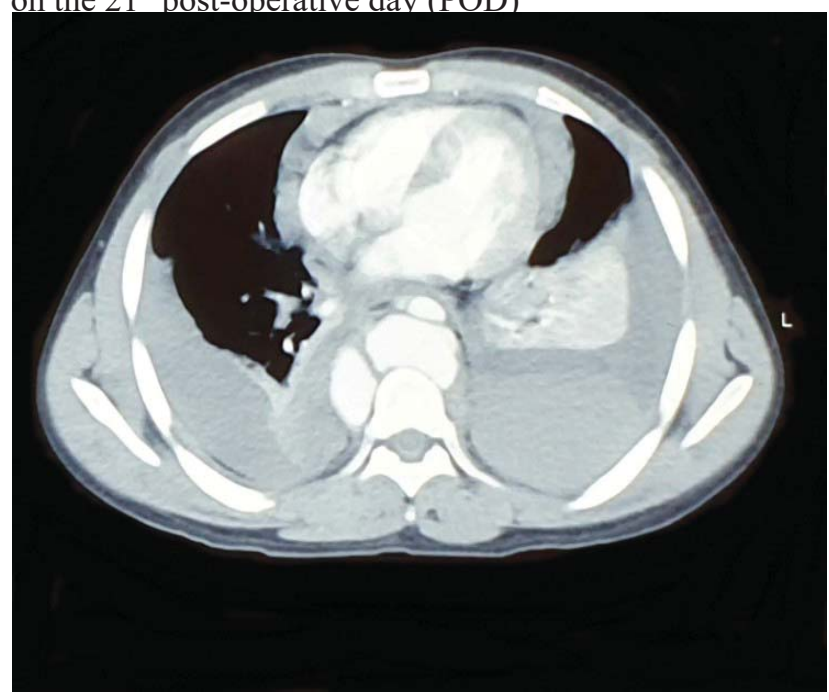

Figure 1. CECT chest showing contrast extravasation from DTA with bilateral hemothorax

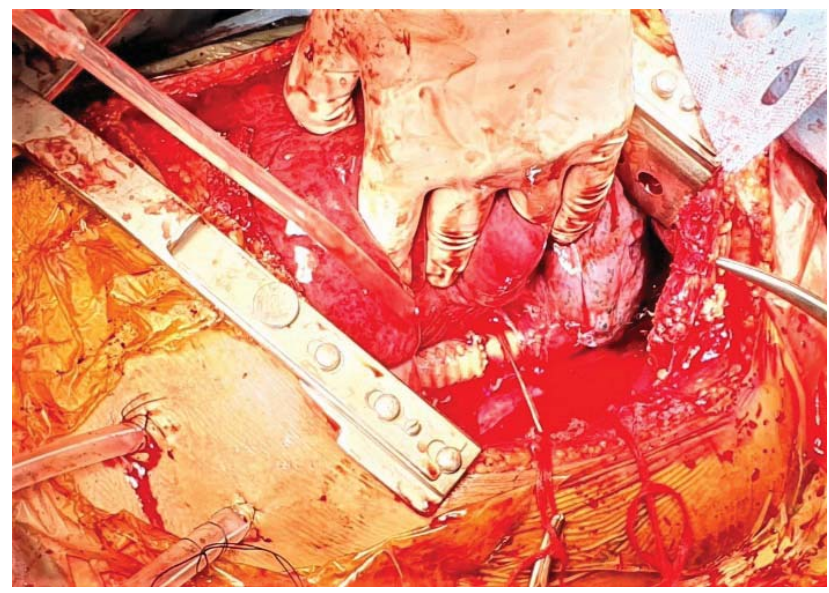

Figure 2. Intraoperative image showing interposed Dacron graft

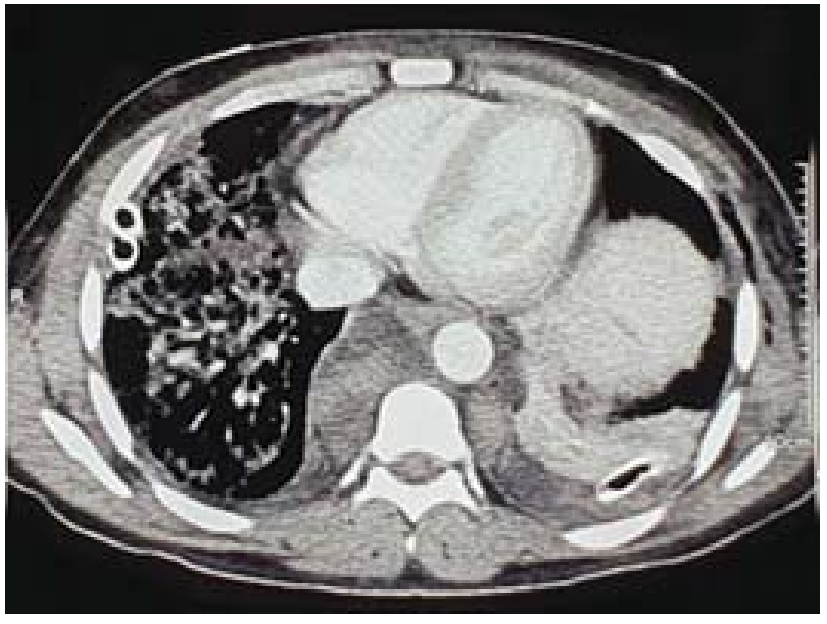

Figure 3. Post-operative CT showing intact graft, no significant collection in thoracic cavity, right lung contusion with consolidation (thoracic drain in situ)

\section{Discussion}

BTAI is a serious condition and seldom encountered by surgeons as less than $25 \%$ of patients with this injury reach the hospital and less than $50 \%$ of them survive beyond 24 hours if left unattended. ${ }^{3}$ In an analysis of the National Trauma Data Bank of the U.S.A., the overall incidence of DTA was found to be just $0.3 \%{ }^{4}$ BTAI are frequent following deceleration type injuries ${ }^{5}$ as DTA is fixed to the spine by preaortic fascia, while the proximal aorta and arch are relatively mobile. This differential fixity develops shear stress in the region of aortic isthmus during rapid deceleration, but this was not the cause in our patient.

The Society for Vascular Surgery Clinical Practice Guidelines suggests urgent $(<24 \mathrm{~h})$ thoracic endovascular repair (TEVAR) for Grade II to Grade IV BTAI. Nonetheless, endovascular treatment is not always feasible and a surgical repair is warranted if such expertise for TEVAR is unavailable or if patients' anatomy is unsuitable for TEVAR. At the time of presentation of this patient, TEVAR was not available immediately with us and hence an urgent surgical repair was undertaken. Although the 'Clamp and Sew' technique established by DeBakey and Cooley $^{6}$ is the standard of care in open repair, one of its major drawbacks was sustaining paraplegia if cross-clamp time exceeded 30 minutes, which was due to diminished distal perfusion with reported incidence up to $16.4 \% .{ }^{3,7}$ To minimize this adverse event of clamp and sew technique, a distal femoro-femoral bypass was employed in our patient and he did not develop paraplegia or paresis. 
Mortality from traumatic ALI is estimated to be $24 \%$ and patients spend an average of 20 days on a ventilator, 22 days in an intensive care unit (ICU), and 32 days in the hospital. ${ }^{9}$ Our patient, despite traumatic ALI, spent a collective ten days on the ventilator, 18 days in the ICU, and was discharged on the $21^{\text {st }}$ POD.

\section{Conclusion}

The current standard of treatment for BTAI is TEVAR but in circumstances where this is not feasible, an open repair can be undertaken with reasonable outcomes. Intraoperative cell salvage systems can be used to minimize blood loss and hence blood transfusion. Femoro-femoral bypass to maintain distal perfusion, close observation for ALI in the post-operative period, and prompt management of complications improve the outcome. A multidisciplinary team approach is required to manage this complex condition.

\section{References}

1. Pant PR, Banstola A, Bhatta S, Mytton JA, Acharya D, Bhattarai S, et al. Burden of injuries in Nepal, 19902017: findings from the Global Burden of Disease Study 2017. Inj Prev. 2020 Jan 8;injuryprev-2019-043309.

2. Azizzadeh A, Keyhani K, Miller CC 3rd, Coogan SM, Safi HJ, Estrera AL. Blunt traumatic aortic injury: initial experience with endovascular repair. J Vasc Surg. 2009 Jun;49(6):1403-8.

3. Fabian TC, Richardson JD, Croce MA, Smith JS, Jr., Rodman G, Jr., Kearney PA, et al. Prospective study of blunt aortic injury: Multicenter Trial of the American Association for the Surgery of Trauma. J Trauma. 1997 Mar;42(3):374-80; discussion 380-3.

4. Arthurs ZM, Starnes BW, Sohn VY, Singh N, Martin MJ, Andersen CA. Functional and survival outcomes in traumatic blunt thoracic aortic injuries: An analysis of the National Trauma Databank. J Vasc Surg. 2009 Apr;49(4):988-94.

5. Nagy K, Fabian T, Rodman G, Fulda G, Rodriguez A, Mirvis S. Guidelines for the diagnosis and management of blunt aortic injury: an EAST Practice Management Guidelines Work Group. J Trauma. 2000 Jun;48(6):1128-43.

6. De Bakey ME. Successful resection of aneurysm of distal aortic arch and replacement by graft. J Am Med Assoc. 1954 Aug 14;155(16):1398-1403.
7. Talaie T, Morrison JJ, O’Connor JV. Blunt thoracic aortic injury. The Journal of Cardiothoracic Trauma. 2018;3(1):11-8.

8. Rubenfeld GD, Caldwell E, Peabody E, Weaver J, Martin DP, Neff M, et al. Incidence and outcomes of acute lung injury. N Engl J Med. 2005 Oct 20;353(16):1685-93.

9. Recinos G, DuBose JJ, Teixeira PGR, Barmparas $\mathrm{G}$, Inaba K, Plurad D, et al. ACS trauma centre designation and outcomes of post-traumatic ARDS: NTDB analysis and implications for trauma quality improvement. Injury. 2009 Aug;40(8):856-9. 